\title{
The use of computers by primary school pupils in Morogoro, Tanzania
}

\author{
Komba, Sotco Claudius $₫ \Delta$ \\ Sokoine University of Agriculture, Tanzania (sotratz@yahoo.com) \\ David, Ndinagwe \\ Mvomero District Council, Tanzania (ndinadav50@gmail.com)
}

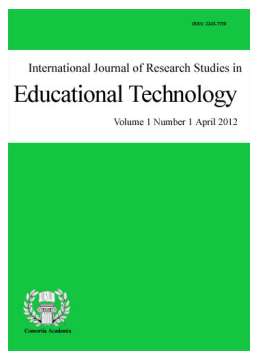

ISSN: 2243-7738

Online ISSN: 2243-7746

Received: 31 January 2016

Revised: 15 February 2016 DOI: $10.5861 /$ ijrset.2016.1431

Accepted: 26 February 2016

OPEN ACCESS

\section{Abstract}

One of the objectives of teaching and learning information and communication technology subject in primary schools is to enable pupils to have abilities to use information technology tools, including computers. This article is based on the study which sought to investigate the extent to which primary school pupils in Tanzania were able to use computers after attending Information and Communication Technology lessons. The specific objectives of the study were four, including: To examine pupils' abilities to start a computer; to use a Microsoft Office Word program; to find information from the internet; and to shut down a computer. The study employed a quantitative research approach in which a case study research design was adopted. A total of 120 pupils from six primary schools in Morogoro Municipality were involved. The data were mainly collected through performance tasks in which the pupils demonstrated their abilities in using computers. The percentages of pupils who were able and those who were unable to perform tasks related to computer use were computed using computer software, Statistical Package for Social Sciences. The main findings were as follows: First, most of the pupils who were involved in this study did not have problems in starting a computer as more than $95 \%$ of the pupils were able to start a computer. Secondly, the majority of pupils had basic skills needed to use a Microsoft Office Word program. Third, more than half of pupils exhibited basic skills for finding information from the internet and a significant proportion of pupils did not have the skills. Lastly, more than $90 \%$ of pupils who were involved in this study were able to shut down a computer. These findings imply that the interactions among pupils, between pupils and teachers and between pupils and information and communication technology materials were effective. In light of these findings, it is recommended that the government should provide all primary schools with computers to enable all pupils in the country develop computer skills which are essential in improving their academic performance.

Keywords: primary school pupils; computers; information and communication technology; Tanzania 


\section{The use of computers by primary school pupils in Morogoro, Tanzania}

\section{Introduction}

The concept of Informational and Communication Technology (ICT) has been defined differently by different scholars. ICT refers to forms of technology that are used for communication and to transmit, store, create, share or exchange information. This definition of ICT includes technologies such as: radio, television, video, telephone (both fixed line and mobile), computer and network hardware and software; as well as the equipment and services associated with these technologies, such as electronic mail, text messaging and radio broadcasts. In the same light, Blurton (1999) defines ICT as a diverse set of technological tools and resources used to communicate, create, disseminate, store, and manage information.

Historically, the teaching and learning of ICT can be traced back before the 1970s in European countries (Pass, 2008). By then, computers and other communication devices such as radios, telephones and televisions were used as teaching and learning devices primarily in tertiary level education institutions. Starting from the mid-19th century, the use of ICTs in schools rapidly expanded in developed nations through curriculum support, networking, professional teachers and software improvements. According to Pass (2008), the application was very ineffective at the initial stage due to the lack of teachers and learners in ICTs. In the late 1980s and early 1990s, the idea to shift from Industrial Society to Information Society came in with the purpose of increasing global information so as to maintain world economies. It is from this time when most of the African countries, including East African countries, started to acknowledge the importance of ICT in development. For example, from the 2000s, ICT started to be taught in Kenya from primary school level to tertiary education level. The teaching of ICT in schools was later adopted in other East African countries, including Tanzania, Uganda, Rwanda and Burundi. The introduction of ICT subject in schools came after realizing the positive effects of ICT use in developed countries such as UK, USA, Austria-Hungary and German (Hennessy \& Onguko, 2010).

Tanzania's National ICT Policy of 2003 acknowledges that ICT offers a new opportunity to improve education in all areas. It is in the same light that the Ministry of Education and Vocational Training posits that the use of ICT in teaching and learning as well as administration and management enables the country to achieve the education and national development objectives.

ICT was introduced as one of the subjects in primary schools in 2005 (TIE, 2005). The subject is called ICT for English medium primary schools and Teknolojia ya Habari na Mawasiliano (TEHAMA) for Kiswahili medium Primary schools. According to TIE (2005), the main objectives of teaching and learning ICT in primary schools include the following: to ensure that pupils are able to use IT tools and information resources effectively in order to analyze and present information; to help pupils realize the role of information and communication technology in social, economic, political and cultural development of a society; to enable learners develop knowledge and skills in the use of information and communication technology facilities; and to acquire knowledge and skills in the use of information and communication technology in teaching and learning process. This study sought to investigate the extent to which primary school pupils in some selected schools in Tanzania were able to use computers after attending ICT lessons.

As pointed out earlier, one of the objectives of teaching and learning ICT subject in primary schools is to enable pupils to have abilities to use ICT tools, including computers (TIE, 2005). A good number of studies on ICT have been conducted globally, including in Tanzania (Konstantinos et al., 2013; Mwolongo, 2011; Balanskat, 2007; \& Candie et al., 2007). The studies have focused on either the impact of ICT in the teaching and learning process or the perceptions of teachers on the introduction of ICT in schools. However, there were hardly any studies which had been conducted to find out the extent to which primary school pupils in Tanzania exhibited abilities in using computers, as stipulated in the syllabus, after attending lessons in ICT subject. 
Therefore, this study was intended to shed light on the identified knowledge gap. The findings of the current study were expected to provide useful information to education stakeholders on whether or not the introduction of ICT subject in schools had benefitted students in terms of developing abilities in using computers. In addition, the findings would add literature to the existing body of knowledge on the topic under investigation. Specifically, this study sought to achieve the following specific objectives: to examine pupils' abilities to start a computer; to examine pupils' abilities to use a Microsoft Office Word programme; to examine pupils' abilities to find information from the internet; and to examine pupils' abilities to shut down a computer.

\section{Literature review}

ICTs can be divided into two groups: Traditional or Old ICTs which include radio and television and the new ICTs which include internet and telecommunications (Desai, 2010). This study focused on the new ICTs in which students' abilities in using computers were examined after attending ICT lessons. The historical development of ICT can be viewed into four phases (ICS, 2012). The first phase is called Mechanical phase which existed between 1770 and 1850. During this phase, ICT was mainly used in water-powered mechanization. The second phase was between 1850 and1900 which was also referred to as a mechanical phase. In this phase, ICT was used in the steam power technology for industrial production. The third phase was between 1900 and1940 and it was called an electromechanical phase which was characterized by the electrification of social and productive organization. The fourth phase which exists up to date started in 1940 and it is called electronic phase. This phase is characterized, among others, by motorization and automation of society, and in the most recent times, by digitalization of the social system.

The current global ICTs can be traced back to the 1750s and 1760s during industrial revolution in Britain and France respectively (Mohamed \& Yarinchi, 2013). The industrialization of these two nations generated a series of scientific inventions in the field of agriculture, transport, communication education, health services, industries and financial institutions. For instance, in the 1960s, there was communication revolution accompanied by new methods of communication which facilitated information sharing. Some of these methods include computer and satellite which have transformed the world into a global village in which interactions among nations, companies and individuals have been simplified.

In East Africa, the genesis of ICT can be traced back to the $19^{\text {th }}$ and $20^{\text {th }}$ centuries when the East African countries began to acknowledge the role of ICT in development. Since then, ICT began to be integrated in industrial production, education, health services, banking and trade organizations so as to cope with the real situation of the informatics society (Mohamed \& Yarinchi, 2013).

In Tanzania, the history of ICT can be traced back to 1960 when the first computer was installed in the office of the Ministry of Finance. Subsequently, in 1974, there were seven computers in the country and since then, ICT began to be intergraded in different economic, social, political and cultural aspects (Mgaya, 2008). The growth of the global informatics society forced Tanzania to start offering courses in computer science and information technology in higher learning institutions. In addition, the Tanzanian government started supplying computers in secondary schools. In 1997, the then Ministry of Education and Culture issued a syllabus for computer studies in secondary schools (Mikre, 2011). This marked the official beginning of the teaching of computer science in Tanzanian secondary schools. Following the convention on Education for All (EFA) which, among others, stressed on the integration of ICT in education, Tanzania formulated an ICT Policy in Education in 2003. In implementing the policy, the Ministry of Education and Vocational Training introduced a curriculum for ICT subject in primary and pre-primary education in 2005 (TIE, 2005). As pointed out earlier in the introductory part of this article, the subject is called ICT for English medium primary schools and Teknolojia ya Habari na Mawasiliano (TEHAMA) for Kiswahili medium Primary schools.

Literature indicates that ICT has a significant role in education. For instance, Oliver (2002) notes that ICT encourages students to take responsibility for their own learning. In other words, the traditional transmissive 
model in teaching and learning process is diminished through ICT model. The student-centred model, which is highly encouraged in today's teaching and learning, is accelerated by ICT as students are enabled to construct their own notes, write individual assignments and make private studies by using computers and internet. In addition, the use of ICT in educational settings acts as catalyst between the student and the teacher as it supports independent learning.

The role of ICT in educational settings is also acknowledged by Balanskat (2007) whose study revealed that pupils were more motivated and attentive for lessons which used ICT devices such as computers, videos, projectors and the related devices. In the same light, Desai (2010) notes that the use of ICT in educational settings improves students' academic performance as study findings indicated that students who used computers in subjects like mathematics, natural science and social science scored higher on tests and examinations. Further findings from Desai's study showed that students who used soft copy, hard copy, DVDs, CD, and related devices performed significantly better than the students who did not use such devices. These findings imply that ICT plays a significant role as far as students' academic achievement is concerned.

According to Blurton (1999), ICT aids in developing virtual educational experience. A virtual educational experience refers to educational situations in which distance and time separate the teacher and student and ICT is used to interact, share, and communicate educational issues. Through email, computer-mediated conferencing $(\mathrm{CMC})$, videoconferencing, or websites, or combinations of these technologies, virtual education helps the student to learn at their own time and place. As a result, educational transactions become accessible at home, working place or anywhere the student chooses to be.

Apart from improving academic achievement and developing virtual educational experience, ICT is also acknowledged for facilitating educational management and administration. In this regard, Oliver (2010) notes that computer software programmes are being used in preparing school timetables, improving the efficient use of time by staff and students, hence reducing administration costs significantly. Therefore, the role of ICT in education cannot be underestimated as it ranges from improving students' academic achievement, through developing virtual educational experience to as far as facilitating educational management and administration.

Many studies on ICT have been conducted inside and outside Tanzania (Aristovnik, 2012; Hatlevik \& Arnseth, 2012; Haggins, 2012; Tondeur et al., 2008; Telda, 2004). For instance, Aristovnik (2012) conducted a study on the impact of ICT on educational performance and its efficiency. The main objective of the study was to review some previous research examining ICT impact on educational output and outcome as well as different conceptual frameworks and methodology related to performance. The findings of the study showed that countries like Finland, Norway, Belgium and Korea were the most efficient countries in terms of ICT when considering educational input and output compared to some less developed countries like Slovakia and Poland. In the study, students' abilities in ICT skills after the completion of ICT courses was not examined, which was the purpose of the current study. In addition, the study was conducted in developed countries while this study was conducted in Tanzania, which is one of the developing nations.

Another study was conducted by Tondeur, Van Keer, Valeko, and Van Braak (2008) on the ICT integration in the classroom: challenging the potential of a school policy in Flemish. The purpose of this study was to examine the local school policy with respect to ICT integration from both the principal's perspective and perceptions of teachers. The findings of this study indicated that teachers used ICT models more regularly than what was required for the models to be employed in the teaching and learning process. Moreover, it was also found that there was ineffective communication between principals and teachers which made teachers fail to integrate ICT properly in the teaching and learning process. However, this study did not focus on student's abilities in using ICT devices and tools, which was the focus of the current study.

Moreover, Telda (2012) conducted a study which sought to understand the importance, impacts and barriers of ICT on teaching and learning in East African countries. In this study, the findings showed that ICT had many benefits to the educational stakeholders as it provided room to explore new knowledge and skills and a 
conducive environment for the teaching and learning process. In addition, it was also revealed that ICT was used to solve complex problems, increased students' motivation, enhanced students' independent learning and helped to reduce teaching load among teachers. Regarding the barriers, the findings revealed that inadequate infrastructure (internet, software, hardware, computers), lack of realistic policy of ICT use, poor teacher welfare and morale, lack of parents and community participation and leaving ICT responsibilities to teachers were main barriers which hindered effective integration of ICT in the teaching and learning process in schools. Nevertheless, the current study sought to make an extra contribution by investigating pupils' abilities in applying ICT skills after attending ICT lessons in Tanzanian primary schools.

Furthermore, Hatlevik and Arnseth (2012) conducted a study on ICT, teaching and leadership. The purpose of this study was to explore the relationship between teachers' experiences with ICT-supportive school leaders, perceived usefulness of computers, perceived learning outcomes for students and teachers' use of computers in their teaching. The findings of this study showed that teachers experiencing ICT-supportive school leaders were more likely to experience supportive colleagues and believed that computers could be useful during classroom instructions. In addition, they spent more time and effort in using computers as part of their classroom than their counterparts who did not have ICT- supportive leaders. However, this study did not focus on pupils' abilities to apply ICT skills, which was the focus of the current study.

In addition, Haggins (2004) conducted a study on the role of ICT in improving teaching and learning process in schools. The findings of this study indicated that ICT offered a wealth of possibilities to support teaching and learning process as computers, for instance, could be used in different ways to improve teaching and learning in schools. However, this study did not investigate pupils' abilities to apply ICT skills after attending ICT lessons which was the focus of the current study.

From the reviewed studies, it is evident that many studies have been conducted globally on the topic under investigation. Most of the studies have focused on impacts, importance, and challenges of integrating ICT in education (Aristovnik, 2012; Tedla, 2012; Hatlevik \& Arnseth, 2012; Balanskat, 2007; Candie et al., 2007; Haggins, 2004) and teachers' perspectives on ICT (Konstantinos et al., 2013; Hatlevik \& Arnseth, 2012; Mwalongo, 2011). In realizing the significance of ICT in education, the government of the United Republic of Tanzania introduced ICT lessons in primary schools in 2005. The students were expected, among others, to acquire knowledge and skills in using ICT tools and devices after attending the lessons. However, there were hardly any studies which had been conducted to find out whether or not this objective was being realized. In this regard, the current study sought to bridge the identified knowledge gap by particularly investigating the extent to which primary school pupils in Tanzania were able to use computers after attending ICT lessons.

\section{Methodology}

This study employed a quantitative research approach in which a case study research design was adopted. The adoption of the quantitative research approach was based on the reason that the study sought to collect numerical data on pupils' abilities to use computers in Tanzanian primary schools. On the other hand, the case study research design was employed because it involves a thorough descriptive analysis of a single individual, group or events (Prince \& Oswald, 2006). In addition, Singh (2006) notes that the case study is useful when researchers seeks to investigate, explore and analyze a single unit such as person, family, institution, culture group or even an entire community to represent the nation or the entire population of a certain region. In this study, the case was standard seven pupils who were involved in ICT lessons. A total of 120 pupils from six primary schools in Morogoro Municipality were involved. The data were mainly collected through performance tasks in which pupils demonstrated their abilities in using computers. The percentages of pupils who were able and those who were unable to perform tasks related to computer use were computed using computer software, Statistical Package for Social Sciences.

\section{Findings and discussion}


Komba, S. C., \& David, N.

\subsection{Pupils' abilities to start a computer}

The first objective of this study was to examine pupils' abilities to start a computer. In order to achieve this objective, the researchers were first interested to examine the extent to which pupils were able to locate and press the power on button. The findings were as shown in Table 1.

Table 1

Pupils' Abilities to locate the power on button

\begin{tabular}{ccccc}
\hline LA & Frequency & Percent & Valid Percent & Cumulative Percent \\
\hline 1 & 6 & 5.0 & 5.0 & 5.0 \\
2 & 4 & 3.3 & 3.3 & 8.3 \\
3 & 110 & 91.7 & 91.7 & 100.0 \\
Total & 120 & 100.0 & 100.0 & \\
\hline
\end{tabular}

Note. LA = Level of Ability; $1=$ Unable; $2=$ Able; $3=$ Very Able

The findings indicated that $95.0 \%$ of the pupils were able to locate the power on button while $5.0 \%$ were unable to do so (Table1). This implies that the majority of the pupils who were involved in this study were able to locate the power on button of the computer. Moreover, the researchers were also interested to find out whether or not the pupils were able to press the power on button. The findings on this aspect were as shown in Table 2 .

Table 2

Pupils' abilities to press the power on button

\begin{tabular}{ccccc}
\hline LA & Frequency & Percent & Valid Percent & Cumulative Percent \\
\hline 1 & 6 & 5.0 & 5.0 & 5.0 \\
2 & 4 & 3.3 & 3.3 & 8.3 \\
3 & 110 & 91.7 & 91.7 & 100.0 \\
Total & 120 & 100.0 & 100.0 & \\
\hline
\end{tabular}

Note. $\mathrm{LA}=$ Level of Ability; $1=$ Unable; $2=$ Able; $3=$ Very Able

Table 2 shows that $95.0 \%$ of the pupils were able to press the power on button in order to start a computer. On the other hand, $5.0 \%$ of the pupils were unable to press the power on button of the computer. These findings imply that the majority of the pupils were able to press the power on button in the process to start a computer. Based on these findings, it seemed that most of the pupils who were involved in this study did not have problems in starting a computer.

\subsection{Pupils'abilities to use a Microsoft office word programme}

The second objective of this study sought to examine pupils' abilities to use a Microsoft Office Word programme. A total of four indicators were used in examining pupils' basic skills in using Microsoft Office Word programme. The first indicator focused on whether or not pupils were able to start a new document. The findings on this indicator were as shown in Table 3.

As shown in Table 3, 85.0\% of the pupils were able to start a new document while the rest (15.0\%) were unable. These findings suggest that the majority of pupils who were involved in this study were able to start a new document in a Microsoft office word programme. 
Table 3

Pupils' abilities to start a new document

\begin{tabular}{ccccc}
\hline LA & Frequency & Percent & Valid Percent & Cumulative Percent \\
\hline 1 & 18 & 15.0 & 15.0 & 15.0 \\
2 & 6 & 5.0 & 5.0 & 20.0 \\
3 & 96 & 80.0 & 80.0 & 100.0 \\
Total & 120 & 100.0 & 100.0 & \\
\hline
\end{tabular}

Note. LA= Level of Ability; 1=Unable; 2=Able; 3=Very Able

The second indicator in this objective focused on whether or not pupils were able to type a document in the Microsoft office word programme. To achieve this, pupils were asked to type the sentences: I am a standard seven pupil at Mtakuja primary school. I like my teachers. The findings for this indicator were as shown in Table 4.

\section{Table 4}

Pupils' abilities to type a document

\begin{tabular}{ccccc}
\hline LA & Frequency & Percent & Valid Percent & Cumulative Percent \\
\hline 1 & 18 & 15.0 & 15.0 & 15.0 \\
2 & 5 & 4.2 & 4.2 & 19.2 \\
3 & 97 & 80.8 & 80.8 & 100.0 \\
Total & 120 & 100.0 & 100.0 & \\
\hline
\end{tabular}

Note. LA= Level of Ability; $1=$ Unable; $2=$ Able; $3=$ Very Able

Table 4 shows that $85 \%$ of the pupils were able to type a new document in the Microsoft office word programme while $15 \%$ of the pupils were unable. Therefore, it seemed that the majority of the pupils were able to type a new document in the Microsoft office programme.

Another indicator focused on whether or not pupils were able to move around a typed document with the aid of a cursor. In this regard, pupils were asked to move the cursor to the word Mtakuja, change its font size, bold it, copy it and paste somewhere within the document. The findings on this aspect were as shown in Table 5.

Table 5

Pupils' abilities to move around a typed document

\begin{tabular}{ccccc}
\hline LA & Frequency & Percent & Valid Percent & Cumulative Percent \\
\hline 1 & 34 & 28.3 & 28.3 & 28.3 \\
2 & 0.8 & 6.7 & 6.7 & 35.0 \\
3 & 78 & 65.0 & 65.0 & 100.0 \\
Total & 120 & 100.0 & 100.0 & \\
\hline
\end{tabular}

Note. $\mathrm{LA}=$ Level of Ability; 1=Unable; 2=Able; 3=Very Able

As indicated in Table 5, 71.7\% of the pupils were able to move around the typed document by using a cursor while $28.3 \%$ were unable. It means that most of the pupils who were involved in this study had the ability to move around a typed document in the Microsoft office word programme.

The last indicator on this objective focused on whether or not the pupils were able to save a typed document. The findings on this aspect were as shown in Table 6. 
Komba, S. C., \& David, N.

\section{Table 6}

Pupils' abilities to save a typed document

\begin{tabular}{ccccc}
\hline LA & Frequency & Percent & Valid Percent & Cumulative Percent \\
\hline 1 & 38 & 31.7 & 31.7 & 31.7 \\
2 & 8 & 6.7 & 6.7 & 38.3 \\
3 & 74 & 61.7 & 61.7 & 100.0 \\
Total & 120 & 100.0 & 100.0 & \\
\hline
\end{tabular}

Note. LA= Level of Ability; 1=Unable; 2=Able; 3=Very Able

Table 6 indicates that the number of pupils who were able to save a typed document constituted $68.4 \%$ of all pupils while those who were unable to do so were $31.7 \%$.

Therefore, in view of the findings of this study, it could be concluded that the majority of pupils had basic skills needed to type a new document using Microsoft Office Word programme.

\subsection{Pupils' Abilities to find information from the internet}

The third objective of this study focused on pupils' abilities to find information from the internet. In this objective, the researchers used three indicators to ascertain whether or not pupils had basic skills required in searching information from the internet. The first indicator focused on whether or not pupils were able to open a web browser, such as Google Chrome, Mozilla Firefox, Internet Explorer and Opera. The findings on this aspect were as shown in Table 7.

Table 7

Pupils' abilities to open a web browser

\begin{tabular}{ccccc}
\hline LA & Frequency & Percent & Valid Percent & Cumulative Percent \\
\hline 1 & 52 & 43.3 & 43.3 & 43.3 \\
2 & 6 & 5.0 & 5.0 & 48.3 \\
3 & 62 & 51.7 & 51.7 & 100.0 \\
Total & 120 & 100.0 & 100.0 & \\
\hline
\end{tabular}

Note. LA= Level of Ability; 1=Unable; 2=Able; 3=Very Able

As shown in Table 7, 56.7\% of the pupils were able to open a web browser while $43.3 \%$ were unable. It means that more than half of the pupils were able to open a web browser and a significant proportion of pupils were unable.

The second indicator focused on whether or not pupils were able to input the right key words in finding information from the internet. In this light, the pupils were asked to search information on examinations results from the National Examinations Council of Tanzania website. The findings on this aspect were as shown in Table 8.

Table 8

Pupils' abilities to input right key words

\begin{tabular}{ccccc}
\hline LA & Frequency & Percent & Valid Percent & Cumulative Percent \\
\hline 1 & 53 & 44.2 & 44.2 & 44.2 \\
2 & 5 & 4.2 & 4.2 & 48.3 \\
3 & 62 & 51.7 & 51.7 & 100.0 \\
Total & 120 & 100.0 & 100.0 & \\
\hline
\end{tabular}

Note. LA= Level of Ability; $1=$ Unable; $2=$ Able; $3=$ Very Able 
Table 8 shows that $56.0 \%$ of the pupils were able to input the right key words in finding information from the internet while $44.0 \%$ of the pupils were unable to do so. Therefore, it seemed that although more than half of the pupils were able to input right key words in searching information from websites, a significant proportion of pupils were unable.

The last indicator for this objective focused on whether or not pupils were able to navigate around a website by using back, forward and refresh buttons. The findings for this indicator were as shown in Table 9.

\section{Table 9}

Pupils' Abilities to navigate around a website

\begin{tabular}{ccccc}
\hline LA & Frequency & Percent & Valid Percent & Cumulative Percent \\
\hline 1 & 58 & 48.3 & 48.3 & 48.3 \\
2 & 18 & 15.0 & 15.0 & 63.3 \\
3 & 44 & 36.7 & 36.7 & 100.0 \\
Total & 120 & 100.0 & 100.0 & \\
\hline
\end{tabular}

Note. LA= Level of Ability; $1=$ Unable; $2=$ Able; $3=$ Very Able

Table 9 indicates that $51.7 \%$ of the pupils were able to navigate around a website by using back, forward and refresh buttons while $48.3 \%$ were unable. These findings imply that the difference between the number of pupils who were able and those who were unable to navigate around a website by using back, forward and refresh buttons was more or less the same.

Therefore, regarding pupils' abilities to find information from the internet, it could be concluded that more than half of students exhibited basic skills required in finding information from the internet and a significant proportion of pupils did not have the skills.

\subsection{Pupil's abilities to shut down a computer}

The last objective of this study sought to examine pupils' abilities to shut down a computer. In achieving this objective, the researchers used four indicators to examine the pupils' abilities to shut down a computer. The indicators were based on the procedures which have to be followed when shutting down a computer. In this regard, the first indicator focused on whether or not pupils were able to close all the opened documents before shutting down a computer. The findings on this aspect were as shown in Table 10.

Table 10

Pupils' abilities to close an opened document

\begin{tabular}{ccccc}
\hline LA & Frequency & Percent & Valid Percent & Cumulative Percent \\
\hline 1 & 26 & 21.7 & 21.7 & 21.7 \\
2 & 6 & 5.0 & 5.0 & 26.7 \\
3 & 88 & 73.3 & 73.3 & 100.0 \\
Total & 120 & 100.0 & 100.0 & \\
\hline
\end{tabular}

Note. LA= Level of Ability; 1=Unable; 2=Able; 3=Very Able

As shown in Table 10, $78.3 \%$ of the pupils were able to close an open document while $21.7 \%$ were unable to do so. This means that the majority of the pupils knew one of the procedures of shutting down a computer, which is to close all open documents.

The second indicator focused on whether or not pupils were able to locate the Start Menu on the desktop. The findings on this indicator were as shown in Table 11. 
Komba, S. C., \& David, N.

\section{Table 11}

Pupils' abilities to locate the Start Menu on the desktop

\begin{tabular}{ccccc}
\hline LA & Frequency & Percent & Valid Percent & Cumulative Percent \\
\hline 1 & 30 & 25.0 & 25.0 & 25.0 \\
2 & 5 & 4.2 & 4.2 & 29.2 \\
3 & 85 & 70.8 & 70.8 & 100.0 \\
Total & 120 & 100.0 & 100.0 & \\
\hline
\end{tabular}

Note. LA= Level of Ability; 1=Unable; 2=Able; 3=Very Able

As presented in Table 11, 75\% of the pupils were able to locate the Start Menu on the desktop whereas $25.0 \%$ of the pupils were unable to locate the same. These findings imply that the majority of the pupils knew another important procedure in shutting down a computer, which is to locate the Start Menu on the desktop.

The researchers were also interested to find out whether or not pupils were able to find the Shutdown item from the Start Menu. The findings on this aspect were as shown in Table 12.

\section{Table 12}

Pupils' abilities to find the Shut Down item from the Start Menu

\begin{tabular}{ccccc}
\hline LA & Frequency & Percent & Valid Percent & Cumulative Percent \\
\hline 1 & 30 & 25.0 & 25.0 & 25.0 \\
2 & 12 & 10.0 & 10.0 & 35.0 \\
3 & 78 & 65.0 & 65.0 & 100.0 \\
Total & 120 & 100.0 & 100.0 & \\
\hline
\end{tabular}

Note. LA= Level of Ability; 1=Unable; $2=$ Able; $3=$ Very Able

Table 12 indicates that $75.0 \%$ of the pupils were able to find the Shut Down item from the desktop while those who were unable constituted $25.0 \%$. This means that most of the pupils knew how to find the Shut Down item from the Start Menu, which is one of the procedures for shutting down a computer.

The last indicator on pupils' abilities to shut down a computer focused on whether or not pupils were able to click the Shutdown item from the Start Menu in order to shut down the computer. Regarding this indicator, the findings were as shown in Table 13.

\section{Table 13}

Pupils' abilities to click the Shut Down item from the Start Menu

\begin{tabular}{ccccc}
\hline LA & Frequency & Percent & Valid Percent & Cumulative Percent \\
\hline 1 & 31 & 25.8 & 25.8 & 25.8 \\
2 & 11 & 9.2 & 9.2 & 35.0 \\
3 & 78 & 65.0 & 65.0 & 100.0 \\
Total & 120 & 100.0 & 100.0 & \\
\hline
\end{tabular}

Note. LA= Level of Ability; $1=$ Unable; $2=$ Able; $3=$ Very Able

As shown in Table 13, 74.2\% of the pupils were able to click the Shut Down item from the Start Menu while $25.8 \%$ were unable. Based on these findings, it seemed that the majority of the pupils were knowledgeable on the procedures to follow when shutting down a computer.

When the findings of this study are carefully examined, the following observations become evident. First, it seemed that most of the students who were involved in this study did not have problems in starting and shutting 
down a computer. This observation could be attributed to the fact that starting and shutting down a computer are basic skills which were easy to teach and learn during ICT lessons. In addition, it could also be an indication that the teacher-pupil interactions during ICT lessons were effective.

Secondly, this study has also revealed that the majority of pupils had basic skills needed to type a new document, using a Microsoft Office Word programme. These findings are not surprising considering that using a Microsoft Office Word programme is one of the basic computer applications. In this regard, it was most likely that teachers put more emphasis in teaching how to use a Microsoft Office Word programme, particularly typing documents.

Third, regarding pupils' abilities to find information from the internet, the findings of this study revealed that more than half of students exhibited basic skills for finding information from the internet. In addition, it also seemed that a significant proportion of pupils did not have the skills needed in finding information from the internet. The fact that most of the pupils were able to find information from the internet could be attributed to the reason that the study was done in an urban setting where internet facilities are readily available, including internet cafes. On the other hand, the observation that a significant proportion of pupils were not able to find information from the internet is attributable to the fact that most of the computers in the visited schools were not connected to the internet. In this regard, it was likely that the teaching of how to find information from the internet was ineffective in the absence of internet connectivity.

It is worth noting that Tanzania has developed a policy on Information and Communication Technology (ICT) for Basic Education (Nyirenda, 2013). The policy capitalizes on integrating ICTs in pre-primary, primary, secondary and teacher education, as well as non-formal and adult education. Nevertheless, the successful implementation of the policy depends on the government's commitment to provide schools with computers as the current experience shows that most private schools in urban centres are already using ICT tools, including computers, while the majority of public schools in both urban and rural areas do not have such tools. To make it more evident, Maro (2014) reports that by 2014, the total number of computers available in Tanzanian primary schools was 7,035 and only $20 \%$ of these computers were found in government schools while the remaining $80 \%$ of the computers were found in non-government schools.

Since most of the schools in Tanzania do not have computers and infrastructures for supporting ICT tools, including computers, it is high time the government committed itself to providing supportive conditions for the integration of ICT in schools. This is particularly important as studies have shown that the use of ICT in educational settings motivates the pupils and improves their academic performance (Desai, 2010; Balanskat, 2007).

\section{Conclusion and recommendations}

One of the objectives of teaching and learning ICT/ TEHAMA in primary schools is to enable pupils to have abilities to use ICT tools, including computers. On the basis of the findings of this study, it seemed that the stated objective was being realized as most of the pupils who were involved in this study exhibited basic skills in using computers. This was an indication that the interactions of pupils with teacher, pupil with pupils, teacher with pupils, and pupils with ICT materials during ICT lessons were, to a great extent, effective. Based on the findings of this study, the following recommendations for implementation are made: First, the government should ensure that all primary schools are equipped with computers. This is due to the fact that only a few primary schools in the study area had computers by the time this study was being conducted. Secondly, it is also recommended that the computers available in the schools should be connected to the internet considering that a significant proportion of pupils who were involved in this study did not have the skills needed to find information from the internet, which was essentially due to the lack of internet connectivity in most of the schools. 


\section{References}

Aristovnik, A. (2012). The impact of ICT on educational performance and its efficiency in selected: A non-parametic analysis. The Turkish Online Journal of Education Technology. http://dx.doi.org/10.2139/ssrn.2187482

Balanskat, A. (2007). Study of the impact of technology in primary schools: Synthesis report. Retrieved from http://eacea.ec.europa.eu/llp/studies/documents/study_impact_technology_primary_school/02_synthesis report_steps_en.pdf

Blurton, C. (1999). New direction of ICT - use in education. UNESCOs World Communication and Information Report: University of Hong Kong. Retrieved from http://www.unesco.org/education/lwf/dl/edict.pdf

Claro, M. (2008). Information and communication technology and educational performance. OECD Background paper for OECD-KERIS expert meeting. Retrieved from http://www.oecd.org/edu/ceri/39485718.pdf

Candie, R., Munro, B., Seagraves L., \& Kenesson, S. (2007). The impact of ICT in schools a landscape review. Quality in Education Center. University of Strathclyde.

Desai, S. (2010). Role of information and commutation technologies in education. New Delhi: Bharati Vidjapeeth's Institute of Computer Application and Management.

Hatlevik, E. O., \& Arnseth, C. H. (2012). ICT, teaching and leadership: How do teachers experience the importance of ICT - supportive school leader? Retrieved from https://www.idunn.no/dk/2012/01/art05

Higgins, S. (2004). Does ICT improve learning and teaching in schools? Newcastle University: British Educational Research Association.

Hennessy, S., Onguko, B., Harrison, D., Ang’odi, K. L., Namalefe, S., Naseem, A., \& Wamakote, L. (2010). Enhancing teaching and learning in East Africa Schools: Review of the literature. Research Report No. 1. astern Africa Centre for Commonwealth Education \& Aga Khan University Institute of Educational Development: University of Cambridge.

Konstantinos, T. (2013). Views of ICT Teachers about the introduction of ICT in primary education in Greece. The Turkish Online Journal of Education Technology, 12(1), 200-209.

Kothari, C. R. (2003). Research methodology. Methods and techniques. New Delhi. New Age International. Kumar, R. (2005). Research methodology. A step-by-step guide for beginners. SAGE Publications.

Maro, N. (2014). The use of computers in public and private primary schools in Tanzania: A digital divide. International Journal of Computer Applications, 103(15), 14-19. http://dx.doi.org/10.5120/18150-9404

Marshall, C., \& Rossman, G. B. (1989). Designing qualitative research. Newbury Park, CA: Sage.

Mikre, F. (2011). The role of information and communication technologies in education: Review article with emphasis to the computer and internet. Ethiopian Journal of Education and Sciences, 6(2), 5.

Mgaya, K. (2008). Development of information technology in Tanzania. Retrieved from http://archive.unu.edu/unupress/unupbooks/uu19ie/uu19ie0i.htm

Mohamed, K., \& Yarinchi, B. M. (2013). Information and communication technology (ICT) and media education: In historical perspectives. European Scientific Journal, 9(20), 198-206.

Mwalongo, A. (2011). Teachers' perceptions about ICT for teaching, professional development, administration and personal use. International Journal of Education and Development Using Information and Communication Technology, 7(3), 36-49.

Nyirenda, M. (2003, December 2). Planning for ICT literacy in public schools in Tanzania. Retrieved from http://www.ippmedia.com/frontend/?1=62206

Oliver, R. (2002). The role of ICT in higher education for the $21^{\text {th }}$ century: ICT as a change agent for education. Edith Cowan University. Western Australia.

Pass, C. (2008). How information and communication technology can support education for sustainable development: current uses and trends. Canada: International Institute for Sustainable Development.

Prince and Oswald. (2006). Observational research by dummies. Fresno: California State University.

Rathy, A. G. (2005). Models of curriculum evaluation. NITTR.

Singh, K.Y. (2006). Fundamental of research methodology and statistics. New Delhi: New Age International Publishers. 
The use of computers by primary school pupils in Morogoro, Tanzania

TIE, (2005). ICT syllabus of primary school standard I-VII. Dar-es-salaam: Tanzania Institute of Education.

Telda, A. B. (2012). Understanding the importance, impacts and barriers of ICT on teaching and learning in East Africa countries. Northeast Normal University Internal Journal for e-learning Security, 2(3/4), 199-207.

Tondeur, J., Van Keer, H., Valcke, M. ,\& Van Braak, J. (2008). ICT integration in the classroom: Challenging the potential of a school policy. Computers and Education, 51(1), 212-223.

http://dx.doi.org/10.1016/j.compedu.2007.05.003 
Komba, S. C., \& David, N. 